\title{
DE HEGEL A LACAN: EL DISCURSO DEL DESEO \\ EN CAMBIO DE ARMAS DE LUISA VALENZUELA
}

POR

\author{
GWENDOLYN Díaz \\ St. Mary's University, Texas
}

¿Qué es lo que quiere la mujer, se pregunta Lacan, el falo, el poder, la palabra o algo más aún? En Cambio de armas Luisa Valenzuela explora varias posibles respuestas a esta interrogativa, para concluir con una pregunta: ¿Qué pasaría si se diera un cambio de armas, o en términos hegelianos, si de víctima esclava la mujer pasara a ser amo opresor? Al concluir el último cuento de esta colección, la protagonista, que ha sido torturada por su amante, toma un revólver, lo levanta y lo apunta hacia las espaldas del hombre que huye. Ahora es ella quien posee el arma y su poder ¿Pero qué hará?

En el transcurso de estos relatos Valenzuela explora ciertas posturas que adopta la mujer que se mueve en un mundo simbólico regido por la supremacía del hombre. Presenta así una crítica del sistema social falocéntrico al mismo tiempo que intenta ensayar la creación de una nueva posibilidad para la mujer: ya sea integrándose al orden simbólico establecido o recreando un lenguaje nuevo que refleje una realidad donde la mujer no es vista en términos de carencia, como señala Lacan, sino de presencia. Lo crucial aquí es la formación de la identidad de la mujer y su sexualización como sujeto caracterizado por la falta. La falta más obvia es la carencia del elemento biológico que lleva a Freud a formular su teoría de la envidia del miembro viril. Lacan muestra que en realidad tal miembro representa otra cosa, lo que él llama el falo y que viene a ser la palabra, la autoridad y el poder. Es decir, la sociedad valora el discurso del hombre y se organiza de acuerdo a tal discurso falocéntrico. La mujer, aunque sí puede moverse en el discurso simbólico de la palabra, es excluida de ese orden en el cual ella se constituye como carente (de falo, de palabra, de poder). El falo como símbolo de poder y significación se convierte en el significante privilegiado (Lacan Ecrits 287). De tal forma la realidad social se organiza de acuerdo al punto de vista patriarcal implícito en el lenguaje, o sea, lo que Lacan llama el orden simbólico.

Los cuentos de Cambio de armas reflejan los conceptos lacanianos de la importancia del lenguaje como agente constitutivo del sujeto. Si consideramos que el lenguaje evidencia un punto de vista que valora los atributos masculinos, la formación de la identidad sexual pone a la mujer en un lugar menos privilegiado. A su vez, los atributos de la mujer son vistos como menos significantes. De esta forma la mujer se posiciona como carencia, dependencia y esclavitud, mientras que el hombre como amo poseedor del falo, de la palabra y del poder. Paralelamente estos relatos encarnan la lucha entre el hombrey la mujer por el reconocimiento 
del valor de su propio ser e ilustran así la dialéctica del amo y del esclavo vista primero en Hegel y reinterpretada por Alexandre Kojève y Jacques Lacan.

Hegel, a quien Lacan lee cuidadosamente, explica la dialéctica del amo y del esclavo en el cuarto capítulo de la Fenomenología del espíritu. Aquí, la conciencia del sujeto sólo es tal cuando tiene ante sí otra conciencia; y así se pierde para encontrarse en el otro cancelando o sublimando al otro, al no verlo como ente real sino como un reflejo de sí mismo. Y así también para el otro individuo, de forma que ambos se reconocen como dos conciencias opuestas ambas buscando su autoidentificación. Esto implica una lucha a muerte en la cual uno se convierte en amo independiente y el otro en esclavo dependiente. El amo es tal porque él tiene el poder de dominar la existencia suya y del esclavo y en consecuencia el esclavo es subordinado por el amo (Hegel 230-35). Alexandre Kojève interpreta esta dialéctica considerando que lo primordial es el deseo humano de reconocimiento:

Desear el Deseo de otro es pues en última instancia desear que el valor que yo soy o "represento" sea el valor deseado por ese otro: quiero que él "reconozca" mi valor como su valor; quiero que él me "reconozca" como un valor autónomo. Dicho de otro modo, todo deseo humano, antropógeno, generador de la Autoconsciencia, de la realidad humana, se ejerce en función del deseo de "reconocimiento" (Kojève 15).

Mientras que para Kojève, también leído por Lacan, la dialéctica del amo y del esclavo trata básicamente de la necesidad de sentirse reconocido, en Lacan lo esencial de esta dialéctica es lo que revela en cuanto a la forma en que se constituye la identidad sexual del sujeto (Lacan, Ecrits 287-88). Es decir, la sexualidad se basa en el deseo, pero no tanto en el deseo de reconocimiento sino en el deseo de lo que falta (Lacan, "Desire in Hamlet" 1516). En el caso de la mujer es el deseo no sólo del falo o del falo como marca significante de una falta, sino también el deseo de autoridad, de posición y de poder dentro del sistema simbólico establecido. Para Lacan todo sujeto se caracteriza por la falta e intenta llenarla con el significante o la palabra. Pero la palabra es incapaz de representar todo el sentido del deseo que la formula. De este hiato surge el motivo de la carencia como condición característica del sujeto. Lacan da nombre a esta falta existencial con el término de "object a" y sugiere que todo ser humano está destinado a la búsqueda perpetua de un significado que siempre se le escapa.

En Cambio de armas la relación entre la sexualidad, la falta y el lenguaje, y el juego del poder y la sumisión se trabajan tanto a nivel conceptual como también formal, dándole a la obra una textura rica y compleja. La colección se inicia con una novela corta, "Cuarta versión", a la que le siguen tres cuentos: "La palabra asesino", "Ceremonias de rechazo" y "De noche soy tu caballo", para concluir con otra novela corta que da título a la obra. La continuidad temática y estructural de los relatos, la repetición de los mismos leitmotivs, la semejanza de la voz narrativa de las protagonistas, la intensidad erótica de cada una de las relaciones, hacen que la obra funcione como una novela de estructura lírica, alrededor de cuyo centro giran las diferentes etapas del desarrollo de la mujer o figura protagónica.

Los leitmotivs funcionan como ejes que estructuran la continuidad de los relatos. El espejo aparece en la mayoría de ellos representando, entre otros significados, los dos lados de cada personaje, la búsqueda de la identidad, el otro como espejo del sujeto hablante y la 
máscara que adopta la mujer. Abundan también las metáforas, la adjetivación y las figuras verbales que denotan el motivo marítimo. Las olas, el viento, las ondas, las ráfagas, la marea se asocian tanto con la emoción erótica como con el miedo y el terror. Las protagonistas parecen navegar, sumergirse, bucear y flotar a la deriva en las relaciones con sus amantes. Las armas son tanto concretas: el rebenque, el revólver, las bombas, el pene; como abstractas: la espera, el miedo, el odio y el falo (poder). Los animales encarnan la bajeza de quien domina con la opresión: el vampiro, el coyote, el lobo; o de quien es sometida como el cordero o montada como un caballo. El cuerpo no es unidad compacta sino un cuerpo desmembrado, un brazo, un ojo, una cara, un pene, una pierna; reflejo de la fragmentación física y psíquica que comenta Lacan. Y las palabras son espejismos resbaladizos con los que se juega, se construye sólo para desconstruir, se crea para denigrar, se denomina para desconcertar. Así ilustran la impotencia del significante que intenta encerrar el significado pero no lo logra, ya que el lenguaje no puede comunicar por completo la realidad.

Abordemos los relatos alterando su orden dado para volver a organizarlos en una secuencia que podría ser cronológica en cuanto van de menor a mayor concientización por parte de las protagonistas. En "De noche soy tu caballo" ella, que casi siempre carece de nombre, recibe la visita de Beto, su amante revolucionario. Le lleva cachaça, un disco de Gal Costa y hacen el amor. La despierta el teléfono con la noticia de que Beto ha muerto y ella dice que no puede ser. Se calla al darse cuenta de que debe ser la policía. En efecto, aparece la policía buscándolo. Ella protege a su amante, a quien nunca delata, y termina en la cárcel tratando de convencerse que la visita de Beto sólo fue un sueño. Este cuento va más allá de los aparentes temas de represión policial y pasión amorosa. Lo interesante aquí es lo que el relato nos dice sobre las palabras. Al llegar, él la toma en sus brazos "sin decir palabra" (105). "Creo que nunca les había tenido demasiada confianza a las palabras" (105), piensa ella; pero enseguida intenta tomar ella la palabra:

\author{
te hacía peleando en el norte \\ te hacia preso \\ te hacía en la clandestinidad \\ te hacía torturado o muerto \\ te hacía teorizando revolución en otro país
}

Pero él responde pidiéndole que calle, diciendo que prefiere no hablar para no romper la "maravilla" de lo que están por hacer juntos. El hablar rompe la maravilla porque introduce la falta, lo que se escapa al significado, lo que produce la angustia. Fuera del orden simbólico del lenguaje, del cual su propio amante la excluye, ella debe conformarse con el acto de amor. El la abraza y le dice: "si de noche sos mi caballo es porque te monto así, asi" (107). Beto asume la postura del amo; la monta y desde su posición superior la domina; ella lo acepta convirtiéndose en su esclava amante. Beto se va y llega la policía. La interrogan y ella no confiesa. Intenta hacer creer a la policía que sólo había soñado con Beto. Heroicamente ella toma la posición de víctima para salvar al hombre que ama. La protagonista es victimizada por un sistema que la excluye del orden simbólico de la palabra, pero que sin embargo la hace presa de los mecanismos sociales de represión que caracterizan a tal orden. Este cuento sobre la confusión entre lo que pasa y lo que se sueña, lo que puede ser o no ser, hace resaltar lo que Lacan señala sobre la ambigüedad del significante que puede 
significar o no significar. Además, subraya la falta de relación entre el hombre y la mujer que buscan la unión en el acto de amor sin nunca sentirse completados.

"Ceremonias de rechazo" comienza con un monólogo sobre la espera. Amanda, la que ama, espera que llame Coyote "Siendo el esperar sentada la forma más muerta de la espera, siendo el esperar la forma menos estimulante de la muerte" (87). ¿Quién es el Coyote, se pregunta? y sabe que él es su deseo: "poco me importa quién es cuando bien sé qué significa para mí y cómo me estimula" (88). Pero comprende que no podrá satisfacerse del todo porque el deseo "es el que nunca está allí donde se lo busca" (92). Lacan diría que el deseo siempre va más allá de la demanda, y lo deseado no alcanza a satisfacer al sujeto. Es evidente aquí que lo que desea Amanda es la satisfacción erótica, pero el Coyote se le niega una vez más y ella le da las espaldas y lo deja atrás. Ahora ya no es él dueño de la situación, sino que ella la controla. De esclava pasa a ser ama de su propia suerte. "Borrón y cuenta nueva", piensa Amanda, descuelga el teléfono y se dedica a una serie de actos de purificación. Primero se quita el rostro que ha lucido con el Coyote aplicándose una máscara de limpieza. Se mira en el espejo como buscando ver quién es, buscando cambiar su cara como si pudiera renacer otra, libre. Conscientemente quiere borrar su cara anterior y dibujarse una nueva. Sabe que el dominio que el hombre tuvo sobre ella la destinaba a la sumisión y lo que quiere es la libertad. Aquí la autora nos describe lo más íntimo de la mujer, las máscaras, la depilación, el baño, el maquillaje y el vestido. Pero mientras que por lo general estos afeites representan el coqueteo de la mujer que intenta atraer al hombre, o la mascarade como lo denomina Lacan, aquí tenemos lo contrario. Amanda intenta despojarse de su apariencia de mujer deseante y encontrarse a sí misma en un rostro y cuerpo limpios, nuevos y puros. Quiere renacer para encontrar su verdadero rostro, la realidad de su ser sin hombre. Y, recordando su infancia, Amanda se deja orinar en el agua de su baño sumergiéndose en la calidez uterina de sus propias aguas para volverse a encontrar frente al espejo bailando desnuda mientras "el espejo le devuelve las formas y le confirma el canto" (101). Rompe con la relación esclavizante con el hombre para pertenecer sólo a sí misma y también para definirse en su propio canto, es decir, su propio lenguaje. Es aquí donde la protagonista comienza a entrar al orden simbólico. Veamos su iniciación en el dominio de la palabra en el siguiente cuento.

"La palabra asesino" es un relato exuberante sobre la interdependencia del lenguaje y el sexo en la formación del sujeto. Se trata de un nacimiento, es decir, al finalizar el cuento ella nace al orden simbólico de la palabra al ponerle nombre a su amante: "ASESINO grita. Y la voz consigue por fin escapar con fuerza de su ser y podría tratarse de un acusación o de un llamado pero se trata en realidad de un parto" (83). Ella "merodeaba por la vida en busca de una respuesta" (67) aunque sabe que no existe y que sólo hay en su lugar el deseo. Esta búsqueda llevaal deseo de significado y de unidad que el sujeto busca tanto en la cadena de significantes como en el acto de amor. Él es presencia, domina el orden simbólico, y con su palabra explica su historia verbalizando su pasado: tiene veintiocho años, estuvo en la cárcel y otras instituciones, peleó en Vietnam, tomó drogas, cometió asesinatos. Ella no tiene la palabra; está fuera del sistema social; es la conciencia narrativa, conciencia y no voz porque la narración toma lugar como monólogo interior. Ella carece de pasado, de historia y de voz, sólo es en función de él y para beneficio de él. Es su espejo en el cual él se busca; un mero reflejo donde él intenta reconocerse y definirse, como el amo que busca ser reconocido y el esclavo que vive subordinado a quien se refleja en él: 
De las piedras que él ha ido echando para sondearse en ella, esta misma noche, ella retiene algunas: la necesidad que él siente de encontrarse a sí mismo, sus dudas ontológicas, los ensueños ... Ella le advierte: No te busques en los espejos, búscate por dentro.Cuidado con la imagen especular. Es falsa. Es invertida, es distante. Te desdobla ... él sin escuchar las advertencias, usándola a ella de espejo, tirándole a la cara la peor de sus caras en procura de autocomprensión (75-6).

La metáfora del espejo recuerda a lo que dice Hegel: lo que buscamos en el otro es a nosotros mismos. Con Lacan vemos lo mismo pero además que la mujer tiende a ser vista como menos significante, y se la relega a una posición inferior considerándola un reflejo incompleto del hombre. Así es excluida del orden simbólico y al mismo tiempo subyugada por él. Tanto el hombre como la mujer se buscan el uno en el otro. Pero el hombre prevalece en el orden social porque domina la palabra, establece la estructura social y la rige por medio del dominio, la sujeción y el poder. Así representa el falo lacaniano o el poder que separa, divide, somete e intimida creando amos y esclavos. La mujer es relegada al orden imaginario, el mundo de los afectos centrado en el espejismo de la unión entre seres humanos, pero es un mundo imaginario porque la unión nunca se logra, siempre hay algo que falta.

¿Cómo es él? se pregunta ella. Es un animal de noche, es una boa constrictora, es oscuro, sedoso, es un leopardo, una pantera negra, es "el repliegue rosado de la piel en esa flor enhiesta, viva" (73). Él es "ese hombre que más que un hombre era la personificación del deseo" (80). Y aquí vemos lo que explica Lacan sobre el deseo, es decir, que el sujeto desea lo que no tiene, lo que le falta; en este caso, el falo, el poder de la palabra, la autoridad del orden social. Pero cuál orden social, piensa ella, ¿el que entrenó a los niños somocistas en la violación y la tortura para deleitarse en la crueldad y la opresión? Ella siente disgusto por el orden o más bien desorden de un mundo como ése. Se rebela contra él, le lanza zarpazos temiendo su propia destrucción. Se enfrenta al orden fálico y lo cuestiona, le hace ver que tampoco tiene respuesta ni significados. Llegando al momento culminante del acto piensa que está viviendo una experiencia de gran intensidad. Pero sabe que las palabras "experiencia", "intensidad" la traicionan, y se siente abandonada "hasta por su propio reino, el del lenguaje" (82). Y esto se entiende al considerar que no es un lenguaje suyo. Es por eso que cuando grita "asesino" y se incorpora al orden simbólico, piensa que va a ser parte del sistema que la ha subyugado "ella misma salir a matar, salir a subvertir el orden porque no hay orden".

En el momento de clímax ella se encuentra en el espacio místico del que habla Lacan en Encore. Es ese momento en que la mujer, no el hombre, siente un goce que va más allá del placer, cerca de la jouissance, que a su vez se relaciona con el placer de la muerte en cuanto representa el estado idílico original (Aún 89-90). Tal perspectiva lacaniana está basada en el concepto de Thanatos desarrollado por Freud. La protagonista "siente que ha atravesado el espejo que está del otro lado ... del deseo" en el espacio del orgasmo, la petite mort, donde el sujeto se pierde. Y en el cuento el deseo erótico conlleva un deseo por la muerte que este amante asesino le pudiera ocasionar. La muerte va unida, según Lacan al del goce o jouissance, y es el absoluto que todos buscamos y que se nos escapa. La jouissance es la realidad que nos esconde el inconsciente y que intentamos vislumbrar en el discurso y en el sexo; una realidad que puede sentir o presentir la mujer en el momento 
del orgasmo, pero que no la puede expresar. Se asemeja a la muerte o a la comunión mística, como se evidencia en la expresión de Santa Teresa en la estatua de Bernini ( $A$ ún 92). Dice Lacan que tanto la jouissance inconsciente como la muerte son los absolutos que buscamos comprender pero que se nos niegan, creando la tensión, la falta, y la división. Pero no hay respuestas, dice el cuento, y no las ofrece; lo que sí ofrece son estas preguntas sobre la posibilidad de un nuevo lenguaje y un nuevo orden más allá del placer fálico, y, cerca, tal vez, del goce erótico de la mujer que Lacan asocia con el acercamiento al insconsciente.

En "Cuarta versión" lo que vemos es la participación de la protagonista dentro del orden simbólico, social y político. Se llama Bella y aunque aún tiene rasgos de la Bella Durmiente, ya se ha despertado a la realidad opresiva que la rodea. Ha entrado de lleno al sistema y maneja las palabras, las máscaras, las ficciones, las historias. Es actriz, sabe adoptar posturas; antes representaba "su propio papel de espera" (5), pero ahora intenta acoplarse al sistema fálico. Para hacerlo debe valerse vicariamente de quién posee la autoridad y así comienza su relación con Pedro, el embajador, el diplomático que por medio de la palabra dirige el ambiente político. Dice Bella, "he aquí una historia que no llega a hacer historia, es pelea por los cuatro costados y se derrama con uñas y con dientes" (4). Como en Hegel, hay una lucha a muerte. El amo es el hombre que domina la situación, pero Bella no se conforma con ser espejo de este hombre. Por medio del embajador, logra ejercer cierto poder; consigue asilo político en la embajada para sus amigos o quien fuera perseguido. Se compromete y se arriesga a la par que se va narrando su historia. Es importante el tema de la narración. Bella es narrada por la voz narrativa del cuento, una persona que recopila las hojas en que Bella ha escrito sus memorias. Tanto la narradora como Bella están conscientes del acto de narrar y del hecho de que la historia de Bella se va creando en el proceso del discurso. Ella está interpretando un nuevo papel, su papel dentro del orden simbólico y al mismo tiempo está ensayando una posibilidad, la posibilidad de integrarse al sistema reinante aunque sea por medio del hombre, quien otorga poder. Bella juega con las palabras, desdobla el lenguaje para desarmarlo y recrear una realidad ambigua. En la cita a continuación, por ejemplo, Bella se burla del famoso giro "he dicho" que refleja (como el "se lo digo yo" de Rayuela) la inflación de un ego que cree poder imponerse como representante de la verdad:

Ha dicho, dijo y dirá, claro, pero tuvo que contradecirse y negarse a sí misma muchas veces y volverse a aceptar y negarse de nuevo y de nuevo contradecirse, hasta recuperar el tiempo lineal ... (6)

También vemos este deleite de jugar con las palabras para cuestionar su sentido en las líneas siguientes:

—Quiénes habrán sido -preguntó Bella.

$-Y$, los parapoliciales, o los paramilitares. Vaya uno a saber.

- Claro. Así queda todo aclarado. O los paracaidistas ¿no? O los parapsicológicos.

- No. Quizá las parafernelias, o las paradentosis, las paráfrasis. No hay que descartar la posibilidad de que fueran mujeres vestidas de hombres.

-Eso. Parafecto. Estamos de parabienes. (34) 
La protagonista se va narrando y al mismo tiempo se va definiendo como mujer. $\mathrm{Ha}$ entrado al orden establecido pero sin tomarse demasiado en serio. Cuando Bella nota la atención que le proporciona el embajador, siente miedo, siente estar bogando a la deriva y "ya no pudo seguir sintiéndose liviana" (14). La relación es descrita en términos de guerra; el embajador es un guerrero que la está matando dulcemente: "tengo una daga amable, redondeada, y tú nunca te quejas cuando te penetra" (41), dice él. Bella no se queja porque lo que quiere es apropiarse de esa daga para manejar el destino político. A ambos los están persiguiendo. Llega el momento de la opción: o se escapa del país con el embajador o se queda en una situación peligrosa. Pero Bella no renunciará a las armas que ha obtenido, aunque sean de otro. Prefiere sacrificar la vida a vivir fuera del orden social y en el silencio. Llega el cambio de armas en la embajada y con él los nuevos guardias que vienen a imponer el orden. Hay un disparo y Bella cae herida en brazos del embajador. Es aquí donde surge la tercera versión, la del tío Ramón o alter ego del embajador que cuenta la historia de Bella después que le pegan el tiro. Una vez más la mujer es silenciada, una vez más es recreada desde el punto de vista del hombre. Tenemos la versión de Bella, la de la narradora, la del tío Ramón y la cuarta es la nuestra, la del lector que construirá la suerte de Bella según su propia perspectiva.

Su suerte podría continuar desarrollándose en el último cuento, "Cambio de armas". Esta protagonista tiene nombre porque se lo han puesto: "le han dicho que se llama Laura" (113). Ha sido recreada tal cual la ha querido concebir su amante. Descubrimos que Laura ha sufrido una herida en la espalda (lo cual recuerda al disparo de Bella), y, que ha perdido la memoria. Es una tabula rasa sobre la cual su amante la dibuja a su gusto. El inscribe pues domina el lenguaje, ella es inscrita porque está fuera de él. La vida de Laura transcurre dentro de un departamento bajo llave donde la mayor parte del tiempo se reposa en la cama esperando al hombre. Y ¿quién es él? Es todos o cualquiera, "el sin nombre al que le puede poner cualquier nombre que pasa por la cabeza, total todos son igualmente eficaces" (114). Su mundo consta sólo de él y ese departamento donde celebran el rito amoroso. Ella teme perderse en el "pozo oscuro" de su inconsciente, y observa su imagen ante el espejo tratando de indagarse sobre su identidad. Pero en el dormitorio, cuando él la obliga a mirarse en el espejo, ella sólo se ve invertida, lejana, desmembrada en piernas, pubis o pechos. El acto de amor no logra constituirla como ser entero, sigue viéndose fragmentada, como el sujeto dividido y descentrado de Lacan (Écrits 4). No se trata tampoco de un acto de amor sino de violencia; al poseerla, él le aplica los nombres con los que la define. Le dice "perra" y "puta", y mientras la va denigrando, él se siente más hombre, más fuerte, mejor que ella. Tal episodio recuerda to que comenta Lacan al decir que el hombre denigra a la mujer y a su cuerpo para sentir que él es superior y que posee alma; siendo ella sólo cuerpo, es inferior (Rose 48-9).

Esta tragicomedia sexual continúa en un episodio donde él, llamado ahora Roque (lo duro, lo pétreo, como Pedro del cuento anterior), deja abierta la mirilla de la puerta para que sus guardaespaldas puedan verlo mientras hace el amor con ella. De esta forma la sigue difiniendo a ella como posesión, presa, esclava deseante; y, a sí mismo como amo, macho, y dominador. Sin embargo esta escena perversa nos dibuja un hombre absurdo y casi ridículo, pues se pasea en su estado de excitación buscando la mirada de su colega para comprobar su hombría. Y nos damos cuenta que él también es un triste ser en busca de la 
mirada del otro para creerse alguien (el reconocimiento del que habla Kojève). Él busca constituirla a ella, en sus propios ojos y los de sus amigos, como esclava poseida, y a sí mismo como amo poderoso. El amor, la muerte y la violencia se amalgaman para producir una realidad estructurada en base a la opresión y la subyugación. Ella comienza a recobrar la memoria; se hunde en ese "pozo" que es su inconsciente y que guarda el secreto de su ser. Él siente la necesidad de decirle que ella ha sido su víctima y él su torturador; que la relación sólo tuvo que ver con su deseo de rebajarla. Es entonces que ella toma el arma que había sido suya, el arma que usó contra este hombre antes de haber sido heriday perder la memoria. La levanta y apunta a las espaldas del hombre. Se produce el cambio de armas. Ella toma el revólver, el falo, el poder y el cuento termina así.

Finalmente, volvamos al asunto de las versiones visto en el cuento anterior y preguntémonos qué versión adoptaría el lector al leer estas páginas. Si ella le dispara con el revólver, será parte del mismo orden cruel que la violara. Si no le dispara seguirá encarnando la pasividad y la sumisión de quien representa la carencia. Este final inconcluso es un acierto por parte de la autora. Pone la conclusión del cuento (y de la obra entera) en manos del lector para que tenga que formular el desenlace adecuado. El problema está en llegar a un final satisfactorio. ¿Si la relación entre el hombre y la mujer es una lucha entre dos seres por el poder, como sugiere Hegel, qué es lo que debe hacer la mujer para evitar ser victimizada por una sociedad que valora la metáfora patriarcal? Para responder acertadamente a este dilema el lector debe considerar que las relaciones vistas en los cuentos de esta colección son ejemplos de una desigualdad injusta. Al mismo tiempo, no se trata tampoco de sustituir un sistema opresivo por otro donde la mujer se convierta en opresora. En "De noche soy tu caballo" la mujer termina victimizada porque elige sacrificarse por su amante. Se entrega a la ideología del hombre a pesar de que ha sido excluida de ese discurso ideológico, ya que se le ha negado la palabra. En "Ceremonias de rechazo" también se la mantiene fuera del mundo de la acción política; su amante le oculta ese quehacer. Pero Amanda opta por crearse una vida propia, borrarse la máscara de sumisión y crearse un rostro libre, independiente y propio. "La palabra asesino" es el cuento más representativo de la colección. Aquí vemos que se trata de la búsqueda de un lenguaje propio, de una historia propia, a partir del momento en que se enuncia por primera vez la palabra. En "Cuarta versión", Bella se despierta del sueño infame de pensar que el valor de la mujer radica en su belleza física. Ella toma su lugar dentro del mundo simbólico de la acción política, aunque deba hacerlo por medio de la intercesión del hombre en quien se apoya. El cuento titular es un descenso a lo más hondo del ser donde la mujer se ha perdido en el inconsciente porque el encontrarse con la realidad de su explotación es demasiado horroroso. Sin embargo logra tomar una acción, logra levantar el revólver.

Para Hegel lo esencial de la relación es justamente eso, que una conciencia sólo es en relación a otra. Somos mutuamente dependientes de las conciencias de quienes se relacionan con nosotros. Para Kojève lo central es el deseo y el deseo básico de todo ser humano es ser reconocido como alguien de valor. Con Lacan vemos que el valor del ser humano depende del orden social establecido, y que ese orden se rige por el lenguaje y las metáforas que manejan quienes controlan el discurso. También sostiene que la característica fundamental del sujeto es que está marcado por la falta, la carencia existencial, que, en el caso de la mujer es la carencia del significante del poder. Otra vez llegamos a la pregunta 
inicial postulada por Lacan: ¿Qué quiere la mujer? En estos cuentos Luisa Valenzuela parece responder que la mujer quiere un nuevo lenguaje, un orden distinto que incluya un punto de vista más amplio, un espacio vital donde forjar una visión menos agresiva. Sugiere que hace falta un discurso que desarrolle una metáfora alternativa que no se base en el dominio y la sumisión a que nos condena Hegel, ni que se estructure según el orden fálico que describe Lacan. En el transcurrir de sus cuentos, la autora crea, deshace y recrea la palabra, se mofa del discurso establecido y ensaya nuevas posibilidades lingüisticas. Comienza a esbozar un espacio discursivo fresco, aún por crear, pero lejos de la opresión y la violencia de la metáfora fálica. En Cambio de armas, Valenzuela da voz a quien, sea hombre o mujer, se ha enfrentado al sistema opresor para rehusarle la autoridad que reclama; da la palabra a quien ha existido en el silencio para decir: "Ya basta. Borrón y cuenta nueva".

\section{Obras Citadas}

Hegel, G.W.F. The Phenomenology of the Spirit. Trans. A.V. Miller. Oxford: Oxford University Press, 1977.

Kojève, Alexandre. La dialéctica del amoy del esclavo en Hegel. Trans. Juan José Sebreli. Buenos Aires: Editorial Pleyade, 1975.

Lacan, Jacques. Aún. Trans. Diana Rabinovich, et. al. Buenos Aires: Ediciones Paidos, 1989.

"Desire and the Interpretation of Desire in Hamlet." Literature and Psychoanalysis.

Ed. Shoshana Felman. Baltimore: Johns Hopkins University Press, 1982. Écrits. A Selection. Trans. Alan Sheridan. Nueva York: W.W. Norton, 1977.

Mitchell, Juliet and Jacqueline Rose. Feminine Sexuality. Jacques Lacan and the École freudienne. Trans. Jacqueline Rose. Nueva York: W.W. Norton, 1982.

Valenzuela, Luisa. Cambio de armas. Hanover: Ediciones del Norte, 1982. 
